\title{
Contribution to the knowledge of the genus Phlebia in Italy
}

\author{
Alessandro Saitta ${ }^{1}$, Cristiano Losi ${ }^{2} \&$ Maria G. Alaimo ${ }^{3}$ \\ ${ }^{1}$ Dipartimento di Scienze Agrarie e Forestali, Università di Palermo, Viale delle Scienze, I-90128 Palermo, Italy. \\ E-mail: alessandro.saitta@unipa.it \\ ${ }^{2}$ Cannaregio 3608, I-30121 Venice, Italy. \\ ${ }^{3}$ Dipartimento di Scienze della Terra e del Mare, Università di Palermo, Via Archirafi 22, I-90123 Palermo, Italy.
}

\begin{abstract}
The presence of two corticioid taxa belonging to the genus Phlebia (Basidiomycota), collected from Sicily, Italy is reported. A macro- and micromorphological descriptions of $P$. acanthocystis and $P$. nothofagi added of ecological and distributional data are here provided. $P$. acanthocystis is reported as new for Italy.
\end{abstract}

\section{INTRODUCTION}

During field investigations in natural Sicilian areas, two uncommon taxa belonging to the genus Phlebia Fr. have been collected: Phlebia acanthocystis Gilb. \& Nakasone, and P. nothofagi (G. Cunn.) Nakasone.

The genus Phlebia includes wood inhabiting corticioid species. Nakasone (1997) after detailed micromorphological and culture studies, and with support from preliminary sequence data formalized the synonymy of Mycoacia Donk with Phlebia.

The species belonging to Phlebia are morphologically different, mostly are resupinate, subgelatinous-ceraceous in the living state and corneous when dry, with smooth to toothed hymenophores. Hyphal system is normally monomitic with clamps; hyphae thin- to thickwalled, smooth or encrusted, tightly agglutinated or more rarely loosely interwoven, with or without a gelatinous matrix. Cystidia absent or present; basidia usually narrowly clavate, in a dense palisade. Basidiospores are hyaline, smooth, thin-walled, allantoid to ellipsoid, nonamyloid, acyanophilous.

\section{MATERIALS AND METHODS}

Descriptions of basidiomes are based on fresh and dried specimens. The macroscopic descriptions were carried out on fresh basidiomata while the microscopic features were observed, under an Olympus BH-2, on dried specimens using a $0.3 \% \mathrm{KOH}$ solution and $0.1 \%$ cotton blue in lactic acid. The spore measurements are based on 50 observations on fresh and dried samples. Studied specimens are deposited in MCVE.
Phlebia ACAnthocystis Gilb. \& Nakasone (Fig. 1) Basidioma effused, $1 \times 3 \mathrm{~cm}$ wide, subceraceous, cream to pale brown, odontoid. Aculei conical to cylindrical, sometimes not distinctly separated towards the base or with conspicuous smooth hymenium between them, rarely apically fimbriate. Margin not particularly differentiated.

Hyphal system monomitic; hyphae thin to slightly thick-walled, hyaline, with clamps, rarely encrusted, $2-5 \mu \mathrm{m}$ wide; distinct and parallel in the centre of the aculei, closely agglutinate and more or less parallel next the substrate. Hyphae densely joined in the subhymenium, loosely interwined into a more open texture in adjacent subiculum. Cystidia infrequent, 40-48 $\mu \mathrm{m}$, variously projecting, thin-walled, subfusiform, attenuated towards the apex that shows short and thin protrusions resembling those of acanthocystidia. Basidia cylindrical to strictly clavate, 16-28×4-4.4 $\mu \mathrm{m}$, tetrasporic, with basal clamps. Basidiospores narrowly ellipsoid or less often cylindrical, thin-walled, smooth, hyaline, mostly with some small guttule, 3.4-4.8 $(5.4) \times 2-2.6 \mu \mathrm{m}$, inamyloid.

Specimen examined: Italy, Sicily, Monte Petroso, Palermo, $550 \mathrm{~m}$ a.s.1., mixed oak wood, on fallen branch of Quercus ilex L., 16 Oct 2011, coll. A. Saitta (MCVE 27791).

Phlebia nothofagi (G. Cunn.) Nakasone (Fig. 2, Fig. 3)

Basidioma resupinate, at first orbicular, ceraceous, hydnoid or somewhat irpicoid. Hymenial surface whitish-cream to ochraceous and finally dark brown, sometimes with grey-violaceous tint towards the base of aculei. Aculei up to $8 \mathrm{~mm}$ 
long. Margine white, fimbriate, sometimes not particularly differentiated. Smell typical, penetrating, with ammoniacal component. Hyphal system monomitic, hyphae with clamps, 2-4 $\mu \mathrm{m}$ wide, thin to slightly thick-walled, hyaline to very pale yellowish-brown; parallel in the centre of the aculei, where sometimes from a clamp origins a slightly thick-walled hypha with pseudoskeletal aspect up 200-300 $\mu \mathrm{m}$ long, and covered with abundant crystals.

Cystidia abundant, metuloid, projecting, fusiform to cylindrical, more or less thick-walled, often with secondary septa, 40-70×3.5-7.2 $\mu \mathrm{m}$. Basidia strictly clavate, tetrasporic, 16-25×4$4.8 \mu \mathrm{m}$. Basidiospores cylindrical to ellipsoidal, smooth, hyaline, thin-walled, 4-6×2.2-3 $\mu \mathrm{m}$, inamyloid.

Specimen examined: Italy, Sicily, Fontana, Palermo, $750 \mathrm{~m}$ a.s.1., mixed wood of Fraxinus angustifolia Vahl, Quercus suber L. and Quercus cerris L. var. gussonei
Borzi, on fallen trunks of $Q$. cerris var. gussonei, 08 Dec 2013, 29 Nov 2013, coll. A. Saitta (MCVE 27792, 27793).

\section{DISCUSSION}

$P$. acanthocystis is characterized by its odontoid light-colored basidioma, the little ellipsoid spores and its characteristic cystidia, not always easily observed (Nakasone \& Gilbertson, 1998). Our collection of $P$. acanthocystis confirms the rarity of cystidial elements in the microscopical structure.

The distribution of $P$. acanthocystis is limited to Hawaii (Nakasone \& Gilbertson, 1998; Hjortstam \& Ryvarden, 2007), Japan (Maekawa et al., 2003), Chile (Gorjón \& Hallenberg 2012), and recently it was collected from the Island de la Réunion (Duhem, 2008). The record of $P$. acanthocystis from Italy can be considered the

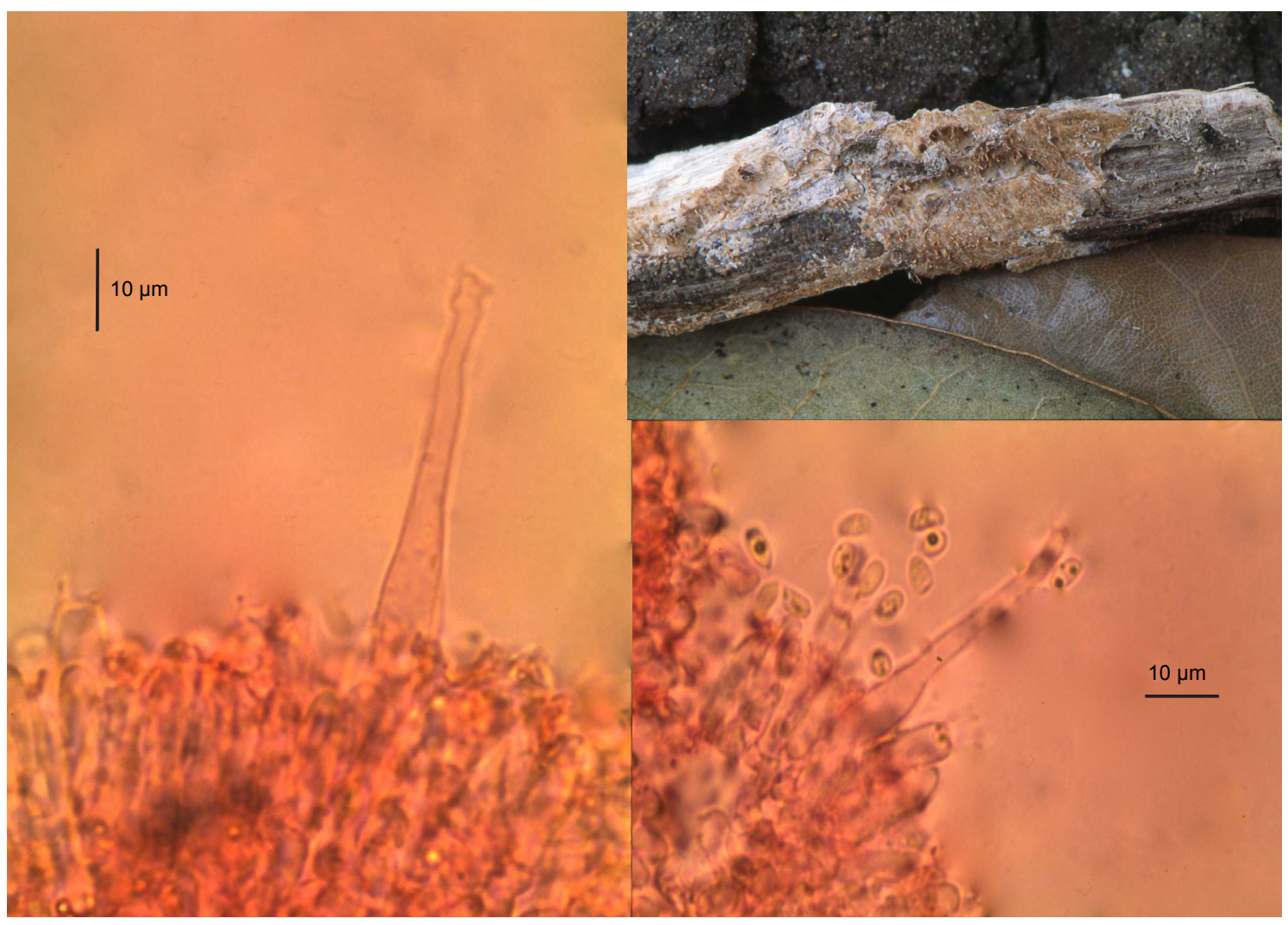

Fig. 1. Basidome and microscopical structures of Phlebia acanthocystis. 


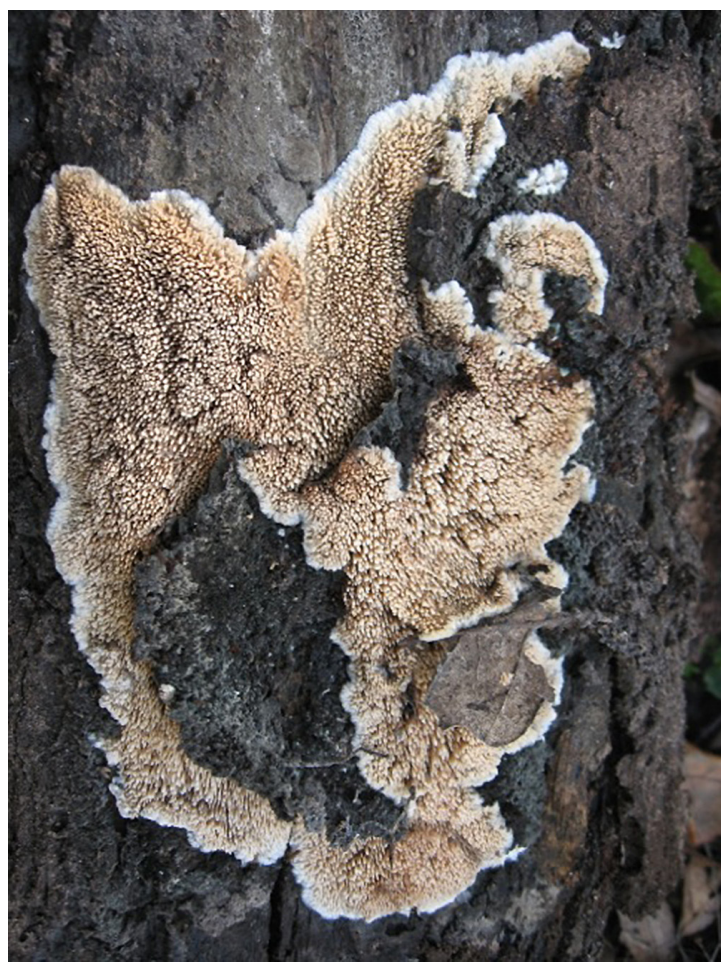

Fig. 2. Basidiome of Phlebia nothofagi. first European record considering the collection from Ile de la Réunion not European.

Macroscopically $P$. nothofagi is very close to P. fuscoatra (Fr.) Nakasone, but the shorter size of the aculei represents a good differential character (Hjortstam et al., 1981, as Mycoacia). Furthermore on the base of microscopical observations $P$. nothofagi and $P$. fuscoatra are easily recognizable for the different shape of cystidia. We have noticed that the very intensive smell, unpleasant with ammonia component, can easily help to individuate this taxon on fresh specimens. The smell of $P$. nothofagi has been previous described as soap-flavour (Reid, 1963), sweetish and nauseating (Martini, 1988) and like Antrodia xantha (Fr.: Fr.) Ryvarden (Losi, 1999).

$P$. nothofagi is widely distributed in Europe but for its limited presence to restricted areas can be considered as an uncommon species. The distribution of $P$. nothofagi in Italy is limited to Veneto (Losi, 1999), Emilia Romagna and Sardinia (Bernicchia \& Gorjón, 2010).

These new collections of uncommon or rare species from Sicily confirm the Sicilian territory as "hotspot" of corticioid species in the Mediterranean area (Saitta et al., 2011).

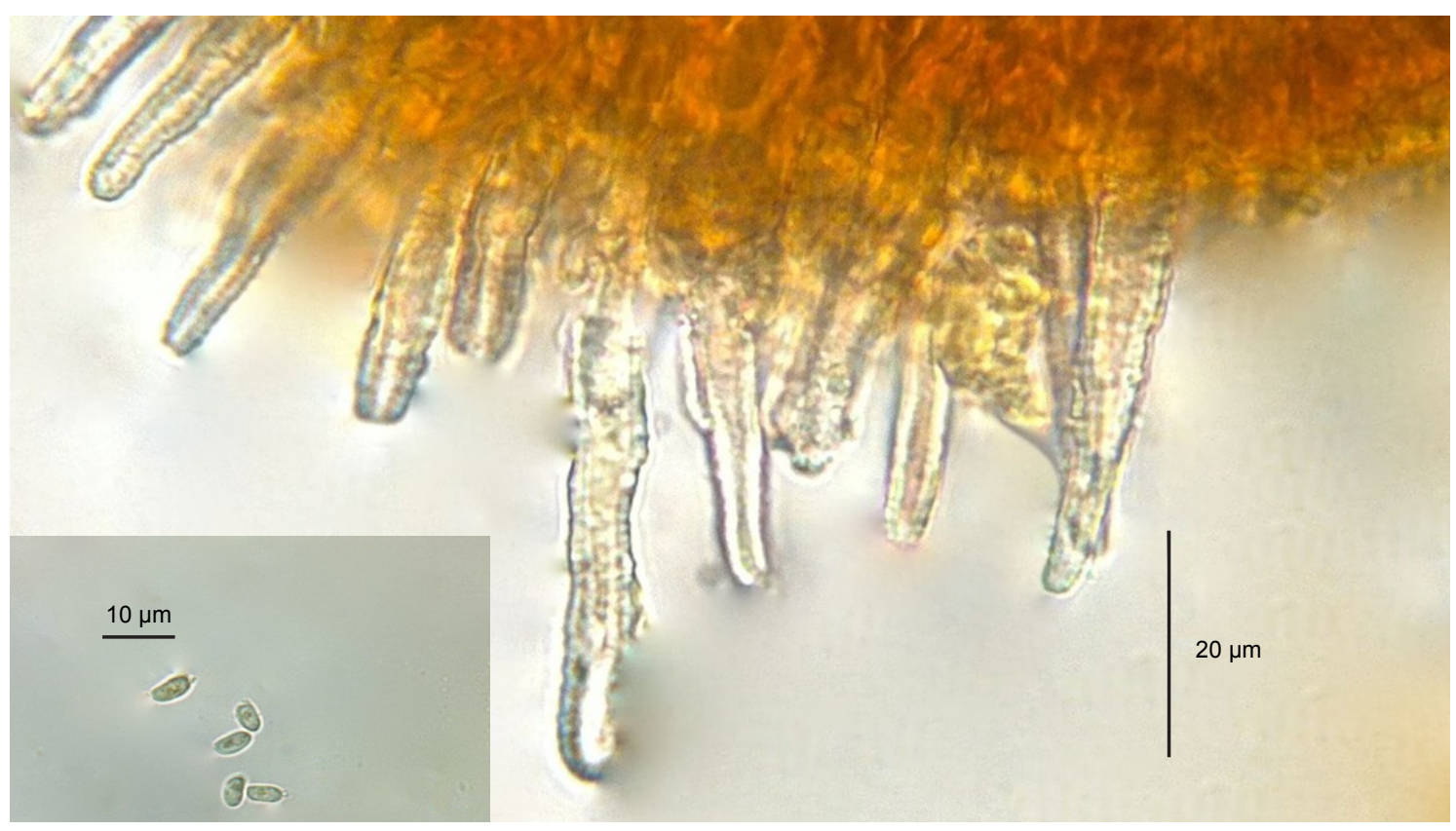

Fig. 3. Cystidia and spores of Phlebia nothofagi. 


\section{REFERENCES}

Baltazar, J. M., Trierveiler-Pereira, L., \& Loguercio-Leite, C. 2009. A checklist of xylophilous basidiomycetes (Basidiomycota) in mangroves. Mycotaxon 107: 221-224. http://dx.doi. org/10.5248/107.221

Bernicchia, A. \& Gorjón, S. P. 2010. Corticiaceae s.1. Fungi Europaei 12. Ed. Candusso, Italia.

Duhem, B. 2008. A propos de plusieurs Phlebia leptocystidiés: Phlebia acanthocystis, P. caspica, $P$. chrysocreas, $P$. ochraceofulva et $P$. subochracea - note sur Phlebia tristis. Bulletin trimestriel de la Société mycologique de France 124: 299-342.

Gorjón, SP. \& Hallenberg, N. 2012. Some new species and a first checklist of corticioid fungi (Basidiomycota) from Chile. Mycological Progress 12: 185-192. http://dx.doi.org/10.1007/s11557012-0824-z

Hjortstam, K. \& Ryvarden, L. 2007. Checklist of corticiod fungi (Basidiomycotina) from the tropics, subtropics and the southern hemisphere. Synopsis fungorum 22: 27-146.

Hjortstam, K., Telleria, M. T., Ryvarden, L. \& Calonge, F. D. 1981. Notes on the Aphyllophorales of Spain. II. Nova Hedwigia 34: 525-538.
Losi, C. 1999. Macrofungus flora of the Lagoon of Venice and adjacent areas (Italy). Non-gilled Basidiomycetes. II. Corticioid fungi. Mycotaxon 64: 243-259.

Maekawa, N., Suhara, H., Kinjo, K. \& Kondo, R. 2003. Corticioid fungi (Basidiomycota) in mangrove forests of the islands of Iriomote and Okinawa, Japan. Mycoscience 44: 403-409. http: / / dx.doi. org/ 10.1007/S10267-003-0133-0

Martini, E. 1988. Alcune interessanti afilloforali resupinate del Ticino. Mycologia Helvetica 3: 73-82.

Nakasone, K. K. 1997. Studies in Phlebia. Six species with teeth. Sydowia 49: 49-79.

Nakasone, K. K. \& Gilbertson, R. L. 1998. Three Resupinate Hydnaceous Basidiomycetes From Hawai'i. Folia Cryptogamica Estonica 33: 85-92.

Reid, D. A. 1963. New or interesting records of Australian Basidiomycetes: V. Kew Bulletin 17: 267-308. http:/ / dx.doi.org/10.2307/4118959

Saitta, A., Bernicchia, A., Gorjòn, S. P., Altobelli, E., Granito, V. M., Losi, C., Lunghini, D., Maggi, O., Medardi, G., Padovan, F., Pecoraro, L., Vizzini, A. \& Persiani, A. 2011. Biodiversity of wood-decay fungi in Italy. Plant Biosystems 145(4): 958-968. http:/ / dx.doi.org/ 10.1080/11263504.2011.6 33114 